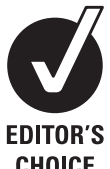

CHOICE

\title{
Educational inequalities in avoidable mortality in Europe
}

\author{
Irina Stirbu, ${ }^{1}$ Anton E Kunst, ${ }^{1}$ Matthias Bopp, ${ }^{2}$ Mall Leinsalu, ${ }^{3,4}$ Enrique Regidor, \\ Santiago Esnaola, ${ }^{6}$ Giuseppe Costa, ${ }^{7,8}$ Pekka Martikainen, ${ }^{9}$ Carme Borrell, ${ }^{10}$ \\ Patrik Deboosere, ${ }^{11}$ Ramune Kalediene, ${ }^{12}$ Jitka Rychtarikova, ${ }^{13}$ Barbara Artnik, ${ }^{14}$ \\ Johan P Mackenbach ${ }^{1}$
}

${ }^{1}$ Department of Public Health, Erasmus MC, University Medical Center Rotterdam, Rotterdam, The Netherlands

Institute of Social and Preventive Medicine, University of Zurich, Zurich, Switzerland ${ }^{3}$ Stockholm Centre on Health of Societies in Transition Södertorn University College, Södertorn, Sweden ${ }^{4}$ Department of Epidemiology and Biostatistics, National Institute for Health Development, Tallinn, Estonia ${ }^{5}$ Department of Preventive Medicine and Public Health, Faculty of Medicine, Universidad Complutense de Madrid,

Madrid, Spain

${ }^{6}$ Research Unit, Department of Health, Basque Government Vitoria-Gasteiz, Spain

${ }^{7}$ Regional Epidemiology Unit, ASL T03 Piedmont Region, Grugliasco, Italy

${ }^{8}$ Department of Clinical and Biological Sciences, University of Turin, Turin, Italy ${ }^{9}$ Department of Sociology, University of Helsinki, Helsinki, Finland

${ }^{10}$ Agència de Salut Pública de Barcelona, Barcelona, Spain ${ }^{11}$ Department of Social Research, Vrije Universiteit Brussel, Brussels, Belgium

${ }^{12}$ Kaunas University of Medicine, Kaunas, Lithuania ${ }^{13}$ Department of Demography and Geodemography, Faculty of Science, Charles University, Prague, the Czech Republic ${ }^{14}$ Department of Public Health Faculty of Medicine, Ljubljana University, Ljubljana, Slovenia

\section{Correspondence to}

Johan Mackenbach,

Department of Public Health,

Erasmus MC, University Medical Centre Rotterdam, P.O. Box 2040, 3000 CA Rotterdam, The Netherlands; j.mackenbach@ erasmusmc.n

Accepted 28 August 2009

Published Online First

14 October 2009

\section{ABSTRACT}

Background The magnitude of educational inequalities in mortality avoidable by medical care in 16 European populations was compared, and the contribution of inequalities in avoidable mortality to educational inequalities in life expectancy in Europe was determined. Methods Mortality data were obtained for people aged 30-64 years. For each country, the association between level of education and avoidable mortality was measured with the use of regression-based inequality indexes. Life table analysis was used to calculate the contribution of avoidable causes of death to inequalities in life expectancy between lower and higher educated groups. Results Educational inequalities in avoidable mortality were present in all countries of Europe and in all types of avoidable causes of death. Especially large educational inequalities were found for infectious diseases and conditions that require acute care in all countries of Europe. Inequalities were larger in Central Eastern European (CEE) and Baltic countries, followed by Northern and Western European countries, and smallest in the Southern European regions. This geographic pattern was present in almost all types of avoidable causes of death. Avoidable mortality contributed between 11 and 24\% to the inequalities in Partial Life Expectancy between higher and lower educated groups. Infectious diseases and cardiorespiratory conditions were the main contributors to this difference.

Conclusions Inequalities in avoidable mortality were present in all European countries, but were especially pronounced in CEE and Baltic countries. These educational inequalities point to an important role for healthcare services in reducing inequalities in health.

\section{INTRODUCTION}

There is worldwide evidence that health status and mortality differ among socioeconomic groups, with those less educated and economically less affluent groups in society being in a more disadvantaged position. $^{1-4}$ It has been suggested that these inequalities may be due, in part, to inequalities in access and quality of health services. ${ }^{5-7}$

Avoidable mortality is a concept, first introduced in 1970, to measure the performance of the healthcare system. $^{8-10}$ It represents mortality from conditions amenable to medical interventions, that is deaths that should have been averted given a timely application of the current medical knowledge and technology. Levels and trends of avoidable mortality have been widely documented. ${ }^{11-19}$ Most researchers have shown that levels of avoidable mortality have substantially decreased over the past 50 years. ${ }^{15}$ 20-22 Studies from the USA, New Zealand and Europe also observed higher levels in avoidable mortality among people disadvantaged in terms of ethnicity or socioeconomic position. ${ }^{13} 23-29$

Evidence on inequalities in avoidable mortality in Europe remains fragmentary with studies limited to particular countries and population groups. In addition, previous studies have limited comparability due to differences in the definition of avoidable mortality, study periods and age groups, and use of different socioeconomic indicators. It is of interest to learn whether there are specific causes of death for which inequalities are large in all European countries. Such causes would point to specific problems with healthcare delivery that require extra attention throughout Europe. In addition, country differences in avoidable mortality can indicate a possible role of specific national healthcare systems, and thus suggest priority areas for more in-depth investigations into the situation of specific countries

The objective of the present study is to estimate the magnitude of educational inequalities in avoidable mortality in different European countries and to prepare such an overview for a wide array of avoidable causes of death. The aim is to obtain indications on the role of the healthcare system in reducing socioeconomic inequalities in health.

\section{METHODS}

Mortality data from 16 European populations (Finland, Sweden, Norway, Denmark, Belgium, Switzerland, Italy, Spain, Slovenia, Hungary, the Czech Republic, Poland, Lithuania and Estonia, table 1) were selected for this study. The data were drawn from national populations, except for Italy (data for Turin city only) and Spain (data for the Madrid and Basque regions, and Barcelona city only). Mortality data for Central and Eastern European (CEE) and Baltic countries, except Slovenia, come from cross-sectional unlinked mortality studies, in which information on socioeconomic data is derived separately from death certificates and census records. Data for other European countries came from longitudinal followup studies, in which socioeconomic position as determined during a census has been linked to mortality.

The list of avoidable causes of deaths was based on the original list developed by Rutstein. ${ }^{9}$ 
Table 1 Descriptive information on the data sources

\begin{tabular}{|c|c|c|c|c|c|c|}
\hline \multirow[b]{2}{*}{ Country } & \multirow[b]{2}{*}{ Type of data } & \multirow[b]{2}{*}{ Follow-up period } & \multirow[b]{2}{*}{ Number of person years at risk } & \multicolumn{3}{|l|}{ Educational level (\%) } \\
\hline & & & & Lower secondary or less & Upper secondary & Post secondary \\
\hline Finland & Longitudinal & $1990-2000$ & 22606143 & 47.2 & 30.9 & 21.8 \\
\hline Sweden & Longitudinal & $1991-2000$ & 36137338 & 37.3 & 43.7 & 19.0 \\
\hline Norway & Longitudinal & $1990-2000$ & 16666847 & 30.2 & 49.4 & 20.4 \\
\hline Denmark & Longitudinal & $1996-2000$ & 11959629 & 43.1 & 36.0 & 20.9 \\
\hline Belgium & Longitudinal & $1991-1995$ & 22349533 & 61.6 & 21.9 & 16.5 \\
\hline Switzerland & Longitudinal & $1990-2000$ & 23663177 & 28.1 & 56.0 & 15.9 \\
\hline Barcelona & Longitudinal & 1992-2001 & 6733310 & 68.0 & 15.2 & 16.8 \\
\hline Madrid region & Longitudinal & $1996-1997$ & 3216098 & 63.3 & 18.9 & 17.8 \\
\hline Basque region & Longitudinal & $1996-2001$ & 5426107 & 67.2 & 18.4 & 14.4 \\
\hline Slovenia & Longitudinal & $1991-2000$ & 8598967 & 45.5 & 43.2 & 11.2 \\
\hline Hungary & CS unlinked & 1999-2002 & 17926668 & 60.4 & 25.9 & 13.7 \\
\hline Czech Republic & CS unlinked & 1999-2003 & 22181655 & 59.5 & 29.1 & 11.4 \\
\hline
\end{tabular}

CS, Cross-sectional.

Specifically, diseases of infectious origin (tuberculosis [A15-19, B90], pneumonia/influenza [J10-18], and other infectious and parasitic diseases [A00-09, A20-99, B00-89, B91-99]); some types of cancer (cervix uteri [C53], testis [C62], Hodgkin's and leukaemia [C81, C91-95]); some conditions that require acute, often operative care (appendicitis, hernia and peptic ulcer [K25-28, K35-38, K40-46, K56] and cholecystitis, lithiasis [K80-83]); and some cardiorespiratory conditions (hypertension and cerebrovascular conditions [I10-15, I60-69], chronic rheumatic heart disease [100-09] and asthma [J45-46]) were selected.

Ischaemic heart disease, colorectal cancer and diabetes were not included, ${ }^{133031}$ as these conditions are to a considerable extent related to lifestyle factors such as smoking, alcohol consumption and obesity, which are known to largely determine socioeconomic inequalities in mortality from these conditions. For the causes of death with strong effect of lifestyle factors, it would be very difficult to determine the extent to which the observed inequalities are caused by the inequalities with regards to medical care rather than inequalities in lifestyle factors. For that reason, these causes of death have been excluded from the study.

The numbers of maternal deaths and deaths caused by prostate hyperplasia were too small to be investigated separately; these causes of death were included only in the group of total avoidable mortality combined.

Analysis of data from longitudinal studies with about 10 years of follow-up was performed among people aged 30-64 (at the start of follow-up). To approximate all populations in terms of average age at death, the analysis was performed on slightly older age groups for all studies with cross-sectional design (35-69 years) and for longitudinal studies with shorter follow-up period (35-69 for Madrid with a 2-year follow-up period, and 30-69 for Belgium and the Basque region with a 5-year follow-up).

Educational level was used as a measure of socioeconomic position. Educational levels were categorised as no or primary education, lower secondary education, upper secondary education and post-secondary/tertiary education. For unlinked crosssectional mortality data, only three educational classes were distinguished (by combining the two lowest educational groups) in order to cope with the numerator/denominator bias problem (see the Discussion section). Information on education was missing for $1.2 \%$ of the population on average. These subjects were excluded from the analysis.
The linkage between census data and mortality registries was achieved for more than $96 \%$ of all deceased persons in almost all populations except Madrid (70\%), the Basque region (93\%) and Barcelona (94.5\%). Evaluations in Madrid and Barcelona observed no variation in this percentage according to age, sex or socioeconomic position. Therefore, estimates of relative inequalities in mortality are not likely to be biased to an important extent. In addition, estimates of the absolute mortality rates were adjusted by increasing these with correction factors (1/0.70, 1/0.93 and 1/0.945 respectively).

To estimate the mortality level per educational level, age-standardised mortality rates were computed using European population as a standard (OECD, 1995). To estimate the extent of inequalities across educational levels, Relative Indices of Inequality (RII) were computed. The RII is a regression-based measure that takes into account the distribution of the population by educational groups. ${ }^{32}$ It assesses the association between mortality rate and the relative position of each educational group. This relative position is measured as the cumulative proportion of each educational group within the educational hierarchy, with 0 and 1 as the extreme values. The RII can be interpreted as the risk of death at the very bottom of the educational hierarchy as compared to the highest end of the educational hierarchy. This measure can be compared between age groups and countries, provided that a detailed and hierarchical classification of educational levels is used in each country. The RII was estimated with log linear regression with control for 5-year age group and gender. The regression model had a log link function and assumed a Poisson error distribution, using the Genmod procedure of SAS. Analyses were conducted for each population separately and combined.

Life table analysis was used to estimate the partial life expectancy (PLE) between the 35th and 70th birthday (with a maximum of 35 years), for higher and lower educational groups. The contribution of each avoidable condition to inequalities in PLE was estimated using the cause elimination life table.

\section{RESULTS}

Inequalities in total avoidable mortality were present in all European populations included in this study (table 2). Compared to the educational inequalities in total mortality, inequalities in total avoidable mortality were slightly larger in all populations 
Table 2 Numbers of death (N), age and sex standardised mortality rates (ASMR), and relative index of inequality (RII) for all-cause mortality and total avoidable mortality by country

\begin{tabular}{|c|c|c|c|c|c|c|c|c|c|c|}
\hline \multirow[b]{3}{*}{ Country } & \multicolumn{5}{|c|}{ All-cause mortality } & \multicolumn{5}{|c|}{ Total avoidable mortality } \\
\hline & \multirow[b]{2}{*}{$\mathbf{N}$} & \multicolumn{2}{|l|}{ ASMR } & \multirow[b]{2}{*}{$\mathbf{R I I}$} & \multirow[b]{2}{*}{$95 \% \mathrm{CI}$} & \multirow[b]{2}{*}{$\mathbf{N}$} & \multicolumn{2}{|l|}{ ASMR } & \multirow[b]{2}{*}{$\mathbf{R I I}$} & \multirow[b]{2}{*}{$95 \% \mathrm{CI}$} \\
\hline & & Lower $\dagger$ education & Higher $\dagger$ education & & & & Lower education & Higher education & & \\
\hline Finland & 141248 & 778.1 & 529.0 & 2.42 & 2.37 to 2.48 & 18085 & 102.0 & 65.0 & 2.78 & 2.60 to 2.97 \\
\hline Sweden & 165512 & 564.7 & 404.5 & 2.01 & 1.97 to 2.05 & 17874 & 62.6 & 42.5 & 2.26 & 2.14 to 2.39 \\
\hline Norway & 87559 & 702.1 & 490.2 & 2.36 & 2.30 to 2.42 & 9836 & 82.6 & 52.5 & 2.78 & 2.57 to 3.01 \\
\hline Denmark & 65510 & 673.6 & 492.3 & 2.30 & 2.23 to 2.37 & 6602 & 70.0 & 48.3 & 2.47 & 2.24 to 2.72 \\
\hline Belgium & 155304 & 730.6 & 563.2 & 1.95 & 1.90 to 1.99 & 16801 & 79.1 & 58.4 & 2.10 & 1.97 to 2.24 \\
\hline Switzerland & 120137 & 581.4 & 486.2 & 2.28 & 2.23 to 2.33 & 13012 & 70.0 & 50.0 & 2.72 & 2.54 to 2.92 \\
\hline Turin & 25579 & 581.6 & 475.6 & 1.66 & 1.59 to 1.75 & 2868 & 64.9 & 51.7 & 1.81 & 1.56 to 2.10 \\
\hline Barcelona & 39101 & 561.7 & 488.5 & 1.72 & 1.65 to 1.79 & 4591 & 66.0 & 53.5 & 1.85 & 1.64 to 2.10 \\
\hline Madrid region & 17180 & 569.7 & 532.1 & 1.56 & 1.47 to 1.66 & 1944 & 66.1 & 55.6 & 1.70 & 1.41 to 2.06 \\
\hline Basque region & 22681 & 427.3 & 442.9 & 1.37 & 1.29 to 1.46 & 2762 & 56.0 & 49.3 & 2.04 & 1.70 to 2.44 \\
\hline Slovenia & 62944 & 845.5 & 691.0 & 2.29 & 2.23 to 2.36 & 9501 & 137.6 & 92.3 & 2.97 & 2.75 to 3.20 \\
\hline Hungary & 201568 & 1351.6 & 687.0 & 4.21 & 4.12 to 4.31 & 31045 & 211.7 & 96.4 & 5.35 & 5.05 to 5.68 \\
\hline Czech Republic & 171397 & 969.6 & 505.9 & 4.36 & 4.26 to 4.47 & 23048 & 134.5 & 63.9 & 5.34 & 4.99 to 5.71 \\
\hline Poland & 394919 & 1124.4 & 551.2 & 4.07 & 4.01 to 4.13 & 57100 & 164.6 & 77.6 & 4.61 & 4.44 to 4.80 \\
\hline Lithuania & 46291 & 1859.2 & 839.9 & 3.50 & 3.37 to 3.64 & 7325 & 293.2 & 128.4 & 4.08 & 3.69 to 4.51 \\
\hline Estonia & 36374 & 1851.8 & 997.1 & 2.90 & 2.79 to 3.03 & 6777 & 350.7 & 178.2 & 3.46 & 3.14 to 3.81 \\
\hline All countries & 1753304 & 885.8 & 573.5 & 2.76 & 2.74 to 2.77 & 229171 & 125.7 & 72.7 & 3.28 & 3.22 to 3.34 \\
\hline
\end{tabular}

*Adjusted for age and sex. A higher Rll indicates greater educational inequalities.

†Lwer education group is a combination of primary or no education and lower secondary education; higher education group is a combination of upper secondary education and tertiary education.

separately and combined. The smallest inequalities in avoidable mortality were observed in South European populations, whereas the largest inequalities were found in CEE and Baltic countries. Relative inequalities were the largest in the Czech Republic and Hungary (5.34) and the smallest in the region of Madrid (1.70). Similar to relative inequalities, larger absolute inequalities in avoidable mortality were observed in CEE and Baltic countries and smaller absolute inequalities were observed in the Spanish regions and Turin.

Large inequalities favouring more educated people in the group of infectious diseases (table 3A) were observed. For all infectious diseases combined, educational inequalities were larger in CEE and Baltic countries and were relatively large also in Denmark (RII 5.04). Nearly all countries had consistently larger inequalities in tuberculosis (TB) mortality than for other infectious diseases. Inequalities in TB mortality were the largest in CEE and Baltic countries, Norway and Denmark, where RIIs peaked at values 10.94 and higher.

Smaller, but consistent, inequalities were found in total avoidable malignant conditions (RII for all countries combined 1.84, CI 1.75 to 1.93 , table $3 \mathrm{~B}$ ). RIIs were slightly lower in the Southern regions, except Madrid and tended to be slightly higher in CEE and Baltic countries, except Slovenia and Estonia. Relative and absolute inequalities (last not shown) were the largest for cervical cancer among women, whereas inequalities for leukaemia and Hodgkin's disease were not consistently present in all countries.

All countries except the Basque region had inequalities by education for all cardiorespiratory conditions combined (table 3C). These inequalities varied between around 1.5 in the Southern population, around 2.5 in Northern and Western European countries and around 4.0 in CEE and Baltic countries. In each country inequalities were approximately equally large for all cardiorespiratory conditions combined, cerebrovascular conditions and chronic rheumatic heart disease (CRHD), but were slightly larger for asthma.

Large educational inequalities in mortality from avoidable acute conditions were present in all countries of Europe (table 3D). The magnitude of inequalities did not vary considerably between specific acute diseases, but it fluctuated largely between countries. Finland, Turin, Hungary, the Czech Republic and Poland had larger educational inequalities in total avoidable acute conditions combined than the European average (all RIIs above 5.00 compared to European average RII 4.50).

Differences in partial life expectancy (PLE) between high and low educational groups were the largest in CEE and Baltic countries, where it varied between 1.72 years in the Czech Republic to 5.07 years in Lithuania (table 4). Slovenia was an exception to the above, having a PLE similar to Nordic countries. The smallest difference in PLE between lower and higher educated groups was in the Basque region (62 days). Avoidable causes of death made a large contribution to these small inequalities $(53 \%)$. In other countries, the contribution of avoidable causes of death to the difference in PLE was between $11 \%$ and $24 \%$. Acute and malignant conditions generally contributed little to the difference in PLE (17\% and less, except in Madrid). Cardiorespiratory and infectious diseases contributed most to the difference in PLE in all European countries. Cardiorespiratory conditions contributed the most to the difference in PLE in Nordic countries, Belgium, Turin, Barcelona and CEE countries, whereas in other countries diseases of infectious origin made the largest contribution.

\section{DISCUSSION}

Educational inequalities in avoidable mortality were present in all countries of Europe and in most types of avoidable causes of death, with the exception of some avoidable malignant diseases. Especially large educational inequalities were found, in relative terms, for infectious diseases and acute conditions. Inequalities were larger in CEE and Baltic countries, followed by Northern and Western European countries and smaller in the Southern European regions. This geographic pattern was present in almost all types of avoidable diseases. Avoidable mortality inequalities contributed between $11 \%$ and $24 \%$ to the difference in PLE between high and low educated groups. Infectious diseases and cardiorespiratory conditions were the main contributors to this difference in PLE. 
Table 3 Numbers of death N, age and sex standardised mortality rates ASMR, and relative index of inequality RIl for groups of avoidable conditions by country

A. Diseases of infectious origin

\begin{tabular}{|c|c|c|c|c|c|c|c|c|c|c|c|}
\hline \multirow[b]{3}{*}{ Country } & \multicolumn{5}{|c|}{ All diseases of infectious origin } & \multicolumn{2}{|c|}{ Tuberculosis } & \multicolumn{2}{|c|}{ Pneumonia/Influenza } & \multicolumn{2}{|c|}{ Other infectious } \\
\hline & \multirow[b]{2}{*}{$\mathbf{N}$} & \multicolumn{2}{|l|}{ ASMR } & \multirow[b]{2}{*}{ RII* } & \multirow[b]{2}{*}{$95 \% \mathrm{Cl}$} & \multirow[b]{2}{*}{ RII* } & \multirow[b]{2}{*}{$95 \% \mathrm{Cl}$} & \multirow[b]{2}{*}{ RII* } & \multirow[b]{2}{*}{$95 \% \mathrm{Cl}$} & \multirow[b]{2}{*}{ RII* } & \multirow[b]{2}{*}{$95 \% \mathrm{Cl}$} \\
\hline & & Lower $\dagger$ education & Higher $\dagger$ education & & & & & & & & \\
\hline Finland & 4053 & 24.4 & 13.1 & 4.21 & 3.65 to 4.86 & 2.73 & 1.68 to 4.44 & 5.72 & 4.79 to 6.84 & 2.00 & 1.50 to 2.68 \\
\hline Sweden & 2955 & 11.5 & 6.4 & 3.17 & 2.75 to 3.66 & 4.75 & 2.09 to 10.77 & 3.80 & 3.15 to 4.57 & 2.30 & 1.83 to 2.90 \\
\hline Norway & 1536 & 13.2 & 8.0 & 2.96 & 2.42 to 3.62 & 10.94 & 4.36 to 27.43 & 3.10 & 2.34 to 4.10 & 2.35 & 1.72 to 3.21 \\
\hline Denmark & 1136 & 14.0 & 6.8 & 5.04 & 3.95 to 6.44 & 14.39 & 4.07 to 50.81 & 6.21 & 4.18 to 9.22 & 3.99 & 2.89 to 5.51 \\
\hline Belgium & 3646 & 17.2 & 12.2 & 2.26 & 1.97 to 2.60 & 3.14 & 1.74 to 5.67 & 4.03 & 3.21 to 5.04 & 1.37 & 1.13 to 1.66 \\
\hline Switzerland & 3950 & 23.4 & 14.9 & 3.77 & 3.32 to 4.28 & 7.47 & 3.05 to 18.30 & 5.51 & 4.36 to 6.97 & 3.08 & 2.64 to 3.59 \\
\hline Turin & 336 & 8.3 & 4.9 & 3.84 & 2.43 to 6.05 & 6.71 & 1.56 to 28.87 & 4.12 & 2.22 to 7.65 & 2.90 & 1.35 to 6.22 \\
\hline Barcelona & 1001 & 15.9 & 10.9 & 3.32 & 2.52 to 4.36 & 9.89 & 4.47 to 21.87 & 2.65 & 1.68 to 4.19 & 2.89 & 1.97 to 4.23 \\
\hline Madrid region & 550 & 19.2 & 15.3 & 2.04 & 1.42 to 2.91 & 4.42 & 1.09 to 17.90 & 2.46 & 1.37 to 4.39 & 1.61 & 1.00 to 2.60 \\
\hline Basque region & 965 & 23.0 & 14.7 & 4.55 & 3.42 to 6.04 & 1.98 & 0.38 to 10.21 & 1.39 & 0.61 to 3.19 & 5.32 & 3.92 to 7.21 \\
\hline Slovenia & 1253 & 19.8 & 10.7 & 5.16 & 4.18 to 6.37 & 13.55 & 7.23 to 25.41 & 5.38 & 4.18 to 6.92 & 2.18 & 1.31 to 3.61 \\
\hline Hungary & 2268 & 16.6 & 5.7 & 9.07 & 7.21 to 11.42 & 15.38 & 10.18 to 23.22 & 10.13 & 7.11 to 14.45 & 3.07 & 1.95 to 4.84 \\
\hline Czech Republic & 3298 & 19.4 & 8.0 & 7.62 & 6.34 to 9.16 & 24.05 & 10.52 to 55.00 & 7.38 & 6.03 to 9.04 & 5.06 & 3.01 to 8.52 \\
\hline Poland & 7724 & 23.5 & 8.4 & 8.12 & 7.23 to 9.10 & 45.47 & 32.39 to 63.83 & 8.22 & 7.02 to 9.64 & 2.98 & 2.44 to 3.63 \\
\hline Lithuania & 1541 & 106.4 & 20.9 & 19.05 & 14.94 to 24.30 & 39.46 & 27.82 to 55.97 & 12.12 & 8.23 to 17.86 & 3.53 & 1.84 to 6.78 \\
\hline Estonia & 1378 & 98.9 & 33.4 & 6.81 & 5.44 to 8.53 & 12.97 & 8.39 to 20.05 & 5.82 & 4.42 to 7.65 & 2.09 & 0.90 to 4.86 \\
\hline All countries & 37590 & 28.4 & 12.2 & 4.69 & 4.48 to 4.90 & 14.68 & 12.77 to 16.88 & 5.46 & 5.12 to 5.82 & 2.52 & 2.34 to 2.71 \\
\hline
\end{tabular}

B. Selected malignant conditions

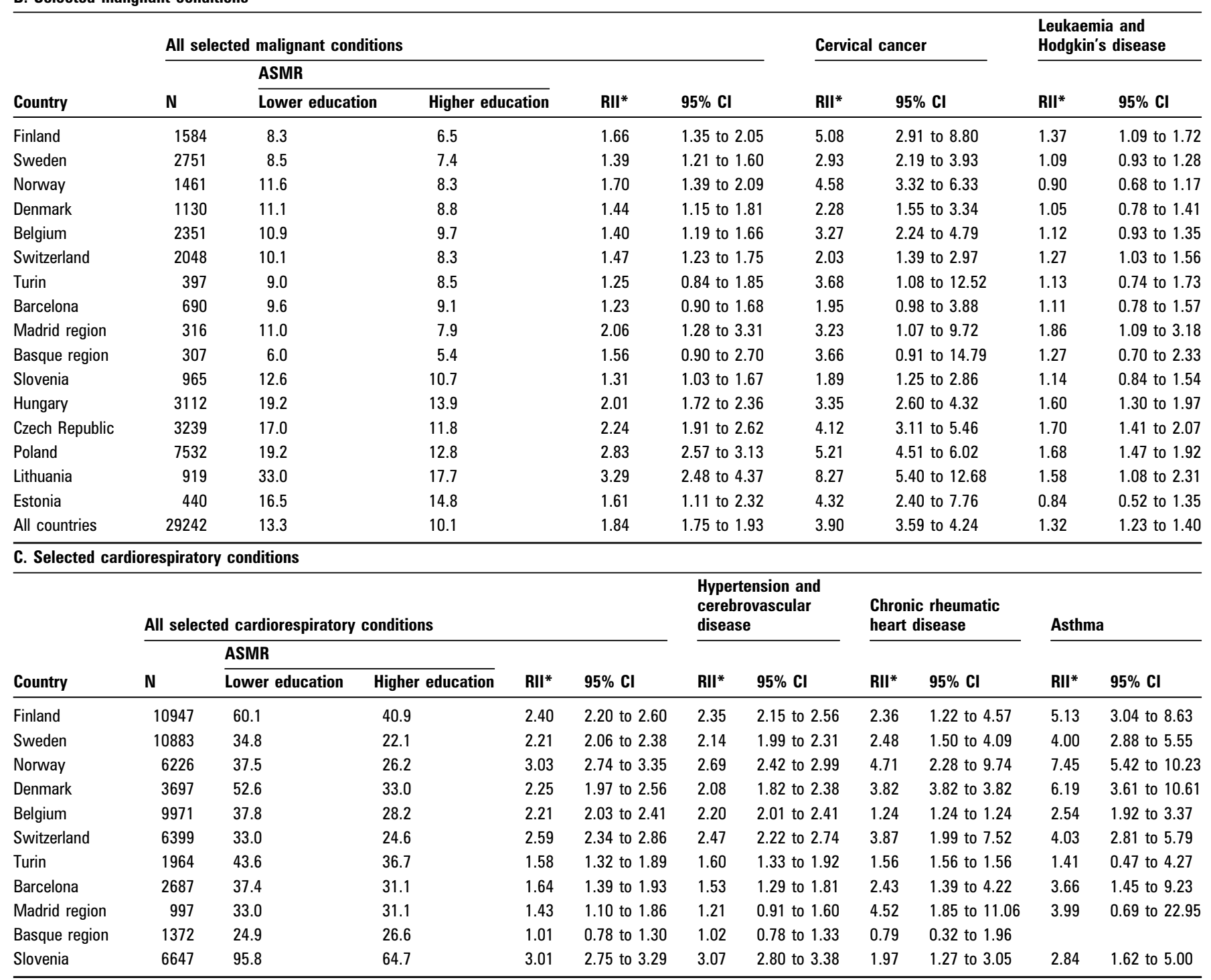

Continued 
Table 3 Continued

\begin{tabular}{|c|c|c|c|c|c|c|c|c|c|c|c|}
\hline \multicolumn{12}{|c|}{ C. Selected cardiorespiratory conditions } \\
\hline \multirow[b]{3}{*}{ Country } & \multicolumn{5}{|c|}{ All selected cardiorespiratory conditions } & \multicolumn{2}{|c|}{$\begin{array}{l}\text { Hypertension and } \\
\text { cerebrovascular } \\
\text { disease }\end{array}$} & \multicolumn{2}{|c|}{$\begin{array}{l}\text { Chronic rheumatic } \\
\text { heart disease }\end{array}$} & \multicolumn{2}{|c|}{ Asthma } \\
\hline & \multirow[b]{2}{*}{$\mathbf{N}$} & \multicolumn{2}{|l|}{ ASMR } & \multirow[b]{2}{*}{$\mathbf{R I I}^{*}$} & \multirow[b]{2}{*}{$95 \% \mathrm{CI}$} & \multirow[b]{2}{*}{ Rll* } & \multirow[b]{2}{*}{$95 \% \mathrm{CI}$} & \multirow[b]{2}{*}{ RII* } & \multirow[b]{2}{*}{$95 \% \mathrm{Cl}$} & \multirow[b]{2}{*}{ RII* } & \multirow[b]{2}{*}{$\mathbf{9 5 \%} \mathbf{C l}$} \\
\hline & & Lower education & Higher education & & & & & & & & \\
\hline Hungary & 23555 & 161.5 & 69.8 & 6.08 & 5.68 to 6.52 & 6.12 & 5.70 to 6.57 & 4.57 & 2.93 to 7.14 & 6.69 & 3.77 to 11.90 \\
\hline Czech Republic & 15059 & 89.5 & 40.5 & 6.02 & 5.53 to 6.56 & 6.12 & 5.61 to 6.68 & 3.76 & 2.45 to 5.78 & 7.29 & 4.02 to 13.24 \\
\hline Poland & 38946 & 113.2 & 52.8 & 4.57 & 4.36 to 4.80 & 4.55 & 4.33 to 4.78 & 4.20 & 3.35 to 5.27 & 6.90 & 5.05 to 9.43 \\
\hline Lithuania & 4501 & 140.3 & 82.8 & 2.76 & 2.45 to 3.12 & 2.63 & 2.31 to 2.99 & 3.91 & 2.52 to 6.04 & 6.83 & 2.69 to 17.33 \\
\hline Estonia & 4645 & 217.8 & 121.8 & 3.08 & 2.74 to 3.45 & 3.11 & 2.77 to 3.50 & 2.11 & 1.14 to 3.91 & 3.14 & 1.51 to 6.51 \\
\hline All countries & 148496 & 75.8 & 45.8 & 3.34 & 3.26 to 3.41 & 3.30 & 3.22 to 3.38 & 3.54 & 3.07 to 4.07 & 4.50 & 4.00 to 5.05 \\
\hline
\end{tabular}

D. Acute conditions

\begin{tabular}{|c|c|c|c|c|c|c|c|c|c|}
\hline \multirow[b]{3}{*}{ Country } & \multicolumn{5}{|c|}{ Total avoidable acute conditions } & \multicolumn{2}{|c|}{$\begin{array}{l}\text { Appendicitis, hernia, } \\
\text { ulcer }\end{array}$} & \multicolumn{2}{|c|}{ Cholecystitis } \\
\hline & \multirow[b]{2}{*}{$\mathbf{N}$} & \multicolumn{2}{|l|}{ ASMR } & \multirow[b]{2}{*}{ RII* } & \multirow[b]{2}{*}{$95 \% \mathrm{CI}$} & \multirow[b]{2}{*}{ RII } & \multirow[b]{2}{*}{$95 \% \mathrm{Cl}$} & \multirow[b]{2}{*}{ RII } & \multirow[b]{2}{*}{$95 \% \mathrm{Cl}$} \\
\hline & & Lower education & Higher education & & & & & & \\
\hline Finland & 1479 & 9.1 & 4.4 & 5.21 & 4.06 to 6.67 & 5.28 & 4.05 to 6.88 & 4.72 & 2.38 to 9.36 \\
\hline Sweden & 1265 & 5.0 & 2.6 & 3.77 & 3.03 to 4.68 & 3.82 & 3.02 to 4.84 & 3.44 & 1.92 to 6.16 \\
\hline Norway & 597 & 5.1 & 3.0 & 3.62 & 2.61 to 5.02 & 3.89 & 2.72 to 5.56 & 2.46 & 1.09 to 5.55 \\
\hline Denmark & 632 & 7.0 & 4.4 & 3.28 & 2.36 to 4.55 & 3.23 & 2.26 to 4.61 & 3.60 & 1.56 to 8.30 \\
\hline Belgium & 811 & 4.0 & 2.4 & 3.03 & 2.22 to 4.14 & 3.02 & 2.13 to 4.28 & 3.08 & 1.50 to 6.32 \\
\hline Switzerland & 600 & 3.4 & 2.1 & 3.97 & 2.87 to 5.50 & 3.94 & 2.76 to 5.63 & 4.13 & 1.89 to 9.05 \\
\hline Turin & 170 & 4.0 & 1.5 & 5.80 & 2.92 to 11.54 & & & & \\
\hline Barcelona & 210 & 3.0 & 2.3 & 2.29 & 1.27 to 4.14 & 2.40 & 1.20 to 4.83 & 2.03 & 0.67 to 6.14 \\
\hline Madrid region & 80 & 2.6 & 2.7 & 1.98 & 0.77 to 5.13 & 3.39 & 0.98 to 11.69 & & \\
\hline Basque region & 105 & 1.9 & 2.4 & 1.55 & 0.58 to 4.09 & 0.92 & 0.30 to 2.80 & 5.74 & 0.74 to 44.55 \\
\hline Slovenia & 626 & 9.2 & 6.3 & 2.98 & 2.22 to 4.00 & 3.05 & 2.23 to 4.18 & 2.50 & 1.09 to 5.71 \\
\hline Hungary & 2086 & 14.2 & 6.8 & 5.19 & 4.15 to 6.49 & 5.63 & 4.43 to 7.17 & 2.81 & 1.56 to 5.09 \\
\hline Czech Republic & 1438 & 8.4 & 3.6 & 7.72 & 5.83 to 10.22 & 7.32 & 5.45 to 9.82 & 12.29 & 4.84 to 31.21 \\
\hline Poland & 2879 & 8.6 & 3.5 & 6.64 & 5.53 to 7.98 & 6.61 & 5.44 to 8.03 & 6.67 & 3.82 to 11.62 \\
\hline Lithuania & 357 & 13.4 & 6.9 & 2.75 & 1.79 to 4.22 & 2.99 & 1.87 to 4.79 & 1.72 & 0.60 to 4.89 \\
\hline Estonia & 303 & 17.2 & 7.9 & 3.36 & 2.13 to 5.29 & 3.94 & 2.41 to 6.44 & 1.23 & 0.38 to 3.98 \\
\hline All countries & 13638 & 7.3 & 3.9 & 4.50 & 4.17 to 4.86 & 4.63 & 4.27 to 5.03 & 3.62 & 2.96 to 4.43 \\
\hline
\end{tabular}

*Adjusted for age and sex.

†Lower education group is a combination of primary or no education and lower secondary education; higher education group is a combination of upper secondary education and tertiary education.

In the present data, education was available in a comparable form for a large number of countries. Advantages of this measure are that it allows for classification of individuals regardless of whether they are inside or outside of the labour force market and it largely averts reverse causation as most people acquire their education early in life. Large differences were observed between countries in the distribution of population by educational level. These differences mainly reflect true variations between countries of Europe in educational systems and attained levels of education. To cope with these differences, the present study used RII, a measure that takes educational distributions into account.

Data from CEE (except Slovenia) and Baltic countries had cross-sectional unlinked design, whereas all other European countries and Slovenia had census-linked mortality follow-up studies. In a study that compares linked and unlinked mortality estimates in Lithuania, Shkolnikov et al demonstrated that mortality inequalities based on unlinked mortality data were overestimated. However, this overestimation was rather small in the age group 30-69. ${ }^{33}$ Moreover, the two lowest educational levels were combined, where numerator denominator bias is most likely to occur, thus minimising possible overestimation of mortality inequalities by education in CEE and Baltic countries. Although residual bias might have remained in the crosssectional studies, it is unlikely to explain the considerably larger educational inequalities in avoidable mortality that were consistently observed in most Baltic and CEE countries.

Although all data came from populations with reliable causeof-death registries, potential influences of national diagnosing and coding practices should also be considered. For example, in Barcelona AIDS cases were coded under a different code and thus were not included in the count of avoidable deaths presented in this study. The results of the present study would be biased only to the extent that coding practices are associated with educational level within populations. The diagnosing and coding practice may have depended on the medical care received before death.

Although there are no specific indications for variations in coding according to the educational level of the deceased, such bias cannot be completely ruled out for some specific smaller causes of death. However, such bias is unlikely to explain the results for broader cause-of-death groups as analysed here.

Particular concern should be given to mortality from HIV/ AIDS. In most of the available data sets, deaths from HIV/AIDS were not included when the 8th or 9th revision of the ICD was used. As a result, HIV/AIDS deaths were not registered for about the first 5 years of the 10-year study periods of Finland, Norway, Sweden and Switzerland (ie, about 1990-1995), and for most of the study periods of Belgium, Barcelona, Madrid, Turin and Slovenia (ie, early and mid-1990s). Due to exclusion of HIV/ 
Table 4 Contribution of causes of death to the difference between low and high educational groups in partial life expectancy (PLE) between ages 35 and 69

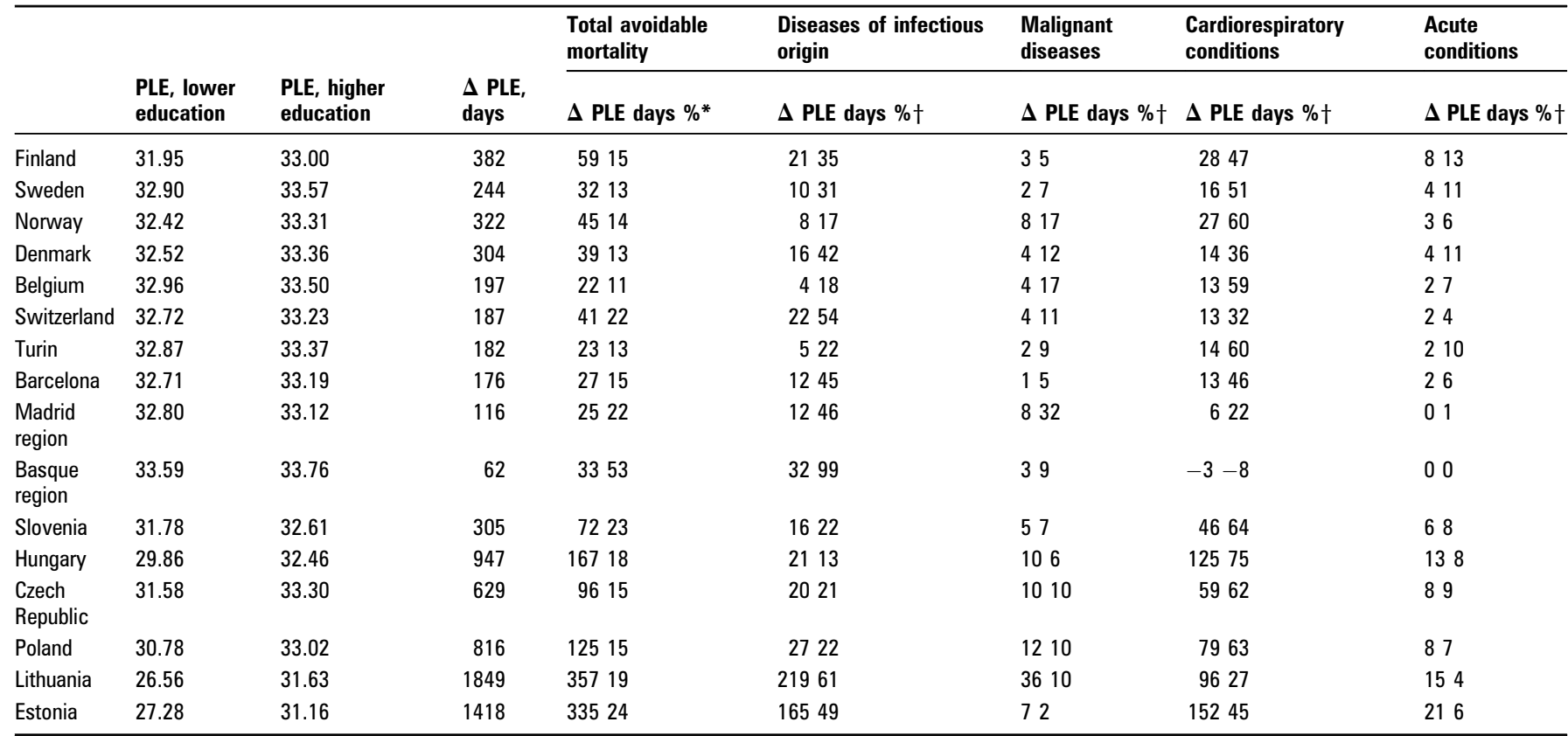

$\Delta \mathrm{PLE}$, difference in PLE between the higher and lower educated groups.

*\% from the total mortality.

$\dagger \%$ from total avoidable mortality.

AIDS deaths, the total burden and the relative inequalities in total avoidable mortality, as well as in mortality from infectious diseases, may have been underestimated. This underestimation may be particularly large for southern European countries, which were severely affected by the AIDS/HIV epidemic in the 1990s. Therefore, it is of special interest to have the results for the Basque country, the only Southern population for which HIV/AIDS deaths were included. The study period for the Basque country, 1996-2001, largely reflects the situation after the introduction of HAART therapy in Spain in about 1997. Compared to Barcelona, Madrid and Turin, higher absolute rates and larger relative inequalities in infectious disease mortality were found in Basque country (table 3A). However, the effect on infectious diseases on educational inequalities in partial life expectancy in the Basque country in 1996-2001 was modest, and much smaller than in Estonia and Lithuania in about 2000 (table 4).

Despite some limitations, the present results are in line with findings from Finland and Sweden, which also show that mortality from avoidable causes of death is higher for people with lower socioeconomic position. ${ }^{23} 28$ The generalised existence of such inequalities in all European countries indicates that the causes for these educational inequalities may go beyond specific characteristics of the individual healthcare systems.

One of the potential explanations of educational inequalities in mortality is inequalities in incidence of the diseases. ${ }^{34-36}$ Social and geographical variations in incidence could partly contribute to the explanation of variations in mortality. Even though inequalities in incidence may be fundamental, these do not always justify the occurrence of inequalities in mortality. Death from many conditions could be prevented (eg, infectious diseases) or considerably delayed even after the condition has developed, provided that appropriate and timely treatment is applied. In addition, occurrence of some diseases can be prevented by medical intervention, for example cervical cancer, influenza and cerebrovascular disease. In these cases, variations in incidence of some conditions may be considered as a possible indication of variations in the quality of preventive care. ${ }^{35}$

Extremely large educational inequalities in TB mortality observed are most likely to be the reflection of higher incidence and prevalence of TB among people with lower socioeconomic position. These inequalities could also be related to delays in initiating anti-TB treatment, as observed in health services in several countries. ${ }^{37-39}$ Diagnostic delays might be reduced through a rigorous screening system of people from high-risk groups (such as migrants, homeless people, drug users and prisoners), an adequate access to care for those who are sick and a high alertness among healthcare professionals.

Cardiorespiratory conditions, of which cerebrovascular mortality is the leading avoidable cause of death, were the largest contributors to the educational inequalities in avoidable mortality in many countries. Although the contribution of behavioural factors such as alcohol consumption, diet, and physical activity to stroke incidence cannot be neglected, a wellorganised hypertension detection and control system is a key measure to prevent deaths from stroke in the population. ${ }^{40} 41$ Additional opportunities within the healthcare system lie in providing better access to, and quality of, services for people with alcohol-related problems and obesity and improving access to emergency care once the condition has developed. The smaller inequalities in cerebrovascular mortality observed in Southern populations are probably related to less socially patterned lifestyle factors (diet, smoking and alcohol consumption ${ }^{42}$ ), and are less likely to be connected to particular achievements of the healthcare system.

Large educational inequalities observed in mortality from acute conditions in all European countries suggest problems with the accessibility, utilisation or quality of acute care for people with lower education. In the USA children and adults with public insurance or those uninsured had a significantly greater chance of having an appendiceal rupture than patients with private insurance. ${ }^{43} 44$ The experiences of people with 
lower and high levels of education in European countries with universal coverage would be instructive in identifying other mechanisms that contribute to educational inequalities with regards to healthcare outcomes. Confidential case reviews might serve as a way to identify and correct possible deficiencies in acute care.

A question is whether inequalities in avoidable mortality between countries observed in this study reflect cross-national variations with regards to healthcare systems. It is especially interesting to learn if it is inequalities in the use of healthcare services or the quality of services received that have the strongest contribution to inequalities in avoidable mortality. International overviews in socioeconomic inequalities in healthcare utilisation ${ }^{5} 45$ show that the magnitude of these inequalities varied little between countries, and any cross-national variations that existed, were not consistently related to the variations in inequalities in avoidable mortality reported here. For example, the magnitude of inequalities in mortality from hypertension or acute conditions strongly differed between Estonia, Hungary and Belgium, whereas these countries had nearly identical inequalities in specialist visits. ${ }^{45}$ This points to a stronger contribution of inequalities in quality of services received rather than overall utilisation patterns. The present results additionally show that the largest contributors to the educational inequalities in avoidable mortality were infectious and cardiorespiratory diseases. These diseases are largely addressed at the primary care level, which could suggest possible shortcomings particularly in the quality of primary care. Evidence suggests that well-organised primary care reduces inequalities in health outcomes and that quality of primary care in general is not lower than that of specialists. ${ }^{46}$ International comparative studies that would investigate differences in quality of primary care in different European countries, however, do not exist.

The geographical scope of this study is substantially broader than that of other studies because a large number of European countries were incorporated, including those in the East, for which data on socioeconomic inequalities in mortality have been poorly documented. It was observed that educational inequalities in avoidable mortality in CEE (except Slovenia) and Baltic countries are larger than in other European countries. These countries had to deal with limited financing, a lack of efficiency and poor quality of health services during the 1990s. This may partly explain the substantially smaller improvements in the mortality from avoidable causes in the East as compared to the rest of Europe. ${ }^{31} 47$ It is notable that the PLE of highly educated people in CEE and Baltic countries was only about 1 year shorter than the PLE of highly educated people in other European countries, whereas the difference in PLE between lower educated people in CEE/Baltic countries and other European countries was more than 3 years (table 4). This finding may indicate that the benefit achieved during the last decade in CEE/Baltic coun-

\section{What is already known on this subject}

- Levels and trends of avoidable mortality have been widely documented.

- Previous studies observed higher levels of avoidable mortality among people disadvantaged in terms of ethnicity or socioeconomic position.

- However, evidence of inequalities in avoidable mortality in Europe remains fragmentary due to limited geographic coverage and comparability of previous studies.

\section{What this study adds}

- The present study found that inequalities in avoidable mortality among people with higher and lower levels of education are present in all European countries and for all avoidable causes of death.

- Educational inequalities were larger in Central Eastern European and Baltic countries, followed by Northern and Western European countries, and smallest in the Southern European regions.

- Avoidable mortality contributed between $11 \%$ and $24 \%$ to the inequalities in Partial Life Expectancy between higher and lower educated groups.

- Educational inequalities in avoidable mortality point to an important role of healthcare services in reducing inequalities in health.

tries primarily was limited to people with higher education, whereas the life expectancy of those in lower education at best stagnated. ${ }^{3}$ Evidence also suggests that access and quality of healthcare services in these countries may play an important role in causing the observed inequalities. ${ }^{48}$ If true, a special priority should be given to improving access and quality of health services for those of lower education in CEE and Baltic countries.

In conclusion, educational inequalities in avoidable mortality are present in all countries of Europe. Reduction of inequalities in cardiorespiratory and infectious diseases would largely contribute to the reduction of the total avoidable mortality in Europe, especially in CEE and Baltic countries. Although socioeconomic inequalities in health are a function of a broad array of factors that go beyond the sphere of influence of healthcare policies and services, the latter may nevertheless contribute to reducing socioeconomic inequalities in mortality.

Acknowledgements The authors thank members of the Eurothine consortium Sara Fritzell (Sweden), Otto Andersen (Denmark), Katalin Kovacs (Hungary), Bogdan Wojtyniak (Poland), and Jens-Kristian Borgan (Norway) for providing the national mortality datasets.

Funding This investigation has been funded by the Health \& Consumer Protection Directorate-General of the European Union and was carried out as a part of the Eurothine project (Grant number 2003125). The study sponsors have not influenced in any form study design, collection, analysis and interpretation of data, writing of the paper and decision to submit it for publication.

\section{Competing interests None.}

Provenance and peer review Not commissioned; externally peer reviewed.

\section{REFERENCES}

1. Huisman $\mathbf{M}$, Kunst $A E$, Bopp $\mathbf{M}$, et al. Educational inequalities in cause-specific mortality in middle-aged and older men and women in eight western European populations. Lancet 2005;365:493-500.

2. Mackenbach JP, Kunst $A E$, Groenhof $F$, et al. Socioeconomic inequalities in mortality among women and among men: an international study. Am J Public Health 1999;89:1800-6.

3. Leinsalu M, Vagero D, Kunst AE. Estonia 1989-2000: enormous increase in mortality differences by education. Int J Epidemiol 2003;32:1081-7.

4. Mackenbach JP, Stirbu I, Roskam AJ, et al. Socioeconomic inequalities in health in 22 European countries. N Engl J Med 2008;358:2468-81.

5. van Doorslaer E, Masseria C, Koolman X, et al. Inequalities in access to medical care by income in developed countries. CMAJ 2006;174:177-83.

6. van Doorslaer $\mathbf{E}$, Wagstaff $A$, van der Burg $H$, et al. Equity in the delivery of health care in Europe and the US. J Health Econ 2000;19:553-83.

7. Etchason J, Armour B, Ofili E, et al. Racial and ethnic disparities in health care JAMA 2001;285:883

8. Charlton JR, Velez R. Some international comparisons of mortality amenable to medical intervention. Br Med J (Clin Res Ed) 1986:292:295-301. 
9. Rutstein DD, Berenberg W, Chalmers TC, et al. Measuring the quality of medica care. A clinical method. N Engl J Med 1976;294:582-8

10. Rutstein DD, Berenberg W, Chalmers TC, et al. Measuring the quality of medical care: second revision of tables of indexes. N Engl J Med 1980;302:1146.

11. Mackenbach JP, Kunst AE, Looman CW, et al. Regional differences in mortality from conditions amenable to medical intervention in The Netherlands: a comparison of four time periods. J Epidemiol Community Health 1988;42:325-32.

12. Malcolm M. Avoidable mortality and life expectancy in New Zealand. J Epidemiol Community Health 1994:48:211.

13. Tobias M, Jackson G. Avoidable mortality in New Zealand, 1981-97. Aust N Z J Public Health 2001;25:12-20.

14. Poikolainen K, Eskola J. Health services resources and their relation to mortality from causes amenable to health care intervention: a cross-national study. Int J Epidemiol 1988;17:86-9.

15. Mackenbach JP, Looman CW, Kunst AE, et al. Post-1950 mortality trends and medical care: gains in life expectancy due to declines in mortality from conditions amenable to medical intervention in The Netherlands. Soc Sci Med 1988;27:889-94.

16. Mackenbach JP, Bouvier-Colle MH, Jougla E. "Avoidable" mortality and health services: a review of aggregate data studies. J Epidemiol Community Health 1990:44:106-11.

17. Logminiene Z, Nolte E, McKee M, et al. Avoidable mortality in Lithuania: 1991-199 compared with 1970-1990. Public Health 2004:118:201-10.

18. Treurniet HF, Boshuizen HC, Harteloh PP. Avoidable mortality in Europe (1980-1997): a comparison of trends. J Epidemiol Community Health 2004;58:290-5.

19. Velkova A, Wolleswinkel-van den Bosch JH, Mackenbach JP. The East-West life expectancy gap: differences in mortality from conditions amenable to medical intervention. Int J Epidemiol 1997;26:75-84.

20. Niti $\mathbf{M}, \mathrm{Ng}$ TP. Temporal trends and ethnic variations in amenable mortality in Singapore 1965-1994: the impact of health care in transition. Int J Epidemiol 2001;30:966-73.

21. Marshall SW, Kawachi I, Pearce N, et al. Social class differences in mortality from diseases amenable to medical intervention in New Zealand. Int J Epidemiol 1993;22:255-61.

22. Albert X, Bayo A, Alfonso JL, et al. The effectiveness of health systems in influencing avoidable mortality: a study in Valencia, Spain, 1975-90. J Epidemiol Community Health 1996;50:320-5.

23. Poikolainen K, Eskola J. Regional and social class variation in the relative risk of death from amenable causes in the city of Helsinki, 1980-1986. Int J Epidemiol 1995;24:114-18

24. Wood E, Sallar AM, Schechter MT, et al. Social inequalities in male mortality amenable to medical intervention in British Columbia. Soc Sci Med 1999;48:1751-8.

25. Stirbu I, Kunst AE, Bos V, et al. Differences in avoidable mortality between migrants and the native Dutch in The Netherlands. BMC Public Health 2006;6:78.

26. Schwartz E, Kofie VY, Rivo M, et al. Black/white comparisons of deaths preventable by medical intervention: United States and the District of Columbia 1980-1986. Int J Epidemiol 1990;19:591-8.

27. Schwarz F. Causes of death contributing to educational mortality disparities in Austria Der Beitrag verschiedener Todesursachen zu bildungsspezifischen Unterschieden in der Mortalitat in Osterreich. Wien Klin Wochenschr 2007;119:309-17.

28. Westerling R, Gullberg A, Rosen M. Socioeconomic differences in 'avoidable' mortality in Sweden 1986-1990. Int J Epidemiol 1996:25:560-7.
29. Westerling R, Rosen M. 'Avoidable' mortality among immigrants in Sweden. Eur J Public Health 2002;12:279-86.

30. Nolte E, McKee M. Does health care save lives? Avoidable mortality revisited. London: Nuffield Trust, 2004.

31. Nolte E, Scholz R, Shkolnikov V, et al. The contribution of medical care to changing life expectancy in Germany and Poland. Soc Sci Med 2002;55:1905-21.

32. Kunst AE, Mackenbach JP. Measuring socio-economic inequalities in health. Copenhagen: World Health Organization, 2000

33. Shkolnikov VM Jasilionis D. Andreev EM, et al. Linked versus unlinked estimates of mortality and length of life by education and marital status: evidence from the first record linkage study in Lithuania. Soc Sci Med 2007;64:1392-406.

34. Bauer RL, Charlton JR. Area variation in mortality from diseases amenable to medical intervention: the contribution of differences in morbidity. Int $\mathrm{J}$ Epidemiol 1986;15:408-12

35. Treurniet HF, Looman CW, van der Maas PJ, et al. Variations in 'avoidable' mortality: a reflection of variations in incidence? Int J Epidemiol 1999;28:225-32.

36. Westerling R. Can regional variation in "avoidable" mortality be explained by deaths outside hospital? A study from Sweden, 1987-90. J Epidemiol Community Health 1996;50:326-33

37. Diez M, Bleda MJ, Alcaide J, et al. Determinants of health system delay among confirmed tuberculosis cases in Spain. Eur J Public Health 2005:15:343-9.

38. Farah MG, Rygh JH, Steen TW, et al. Patient and health care system delays in the start of tuberculosis treatment in Norway. BMC Infect Dis 2006:6:33.

39. Paynter S, Hayward A, Wilkinson P, et al. Patient and health service delays in initiating treatment for patients with pulmonary tuberculosis: retrospective cohort study. Int J Tuberc Lung Dis 2004;8:180-5.

40. Lewington S, Clarke R, Qizilbash N, et al; Prospective Studies Collaboration. Agespecific relevance of usual blood pressure to vascular mortality: a meta-analysis of individual data for one million adults in 61 prospective studies. Lancet 2002;360:1903-13

41. Lawes CM, Bennett DA, Feigin VL, et al. Blood pressure and stroke: an overview of published reviews. Stroke 2004:35:776-85.

42. Mackenbach JP, Cavelaars AE, Kunst AE, et al. Socioeconomic inequalities in cardiovascular disease mortality; an international study. Eur Heart $J$ 2000;21:1141-51.

43. Ponsky TA, Huang ZJ, Kittle K, et al. Hospital- and patient-level characteristics and the risk of appendiceal rupture and negative appendectomy in children. JAMA 2004;292:1977-82

44. Braveman $\mathbf{P}$, Schaaf VM, Egerter S, et al. Insurance-related differences in the risk of ruptured appendix. The New England journal of medicine 1994;331:444-9.

45. Stirbu I. Inequalities in utilisation of GP and specialist services in 9 European countries. Inequalities in health, does health care matter? Thesis. Rotterdam: Erasmus University, 2008

46. Starfield B, Shi L, Macinko J. Contribution of primary care to health systems and health. The Milbank Quarterly 2005;83:457-502.

47. Boys RJ, Forster DP, Jozan P. Mortality from causes amenable and non-amenable to medical care: the experience of eastern Europe. BMJ 1991;303:879-83.

48. Walters S, Suhrcke M. Socioeconomic inequalities in health and health care access in central and eastern Europe and the CIS: a review of the recent literature. Copenhagen: WHO European Office for Investment for Health and Development, 2005. 